\title{
Assessing the Governance Capacity of Cities to Address Challenges of Water, Waste, and Climate Change
}

\author{
S. H. A. Koop ${ }^{1,2} \cdot$ L. Koetsier ${ }^{1}$ - A. Doornhof ${ }^{1}$ • \\ O. Reinstra ${ }^{3}$ - C. J. Van Leeuwen ${ }^{1,2} \cdot$ S. Brouwer ${ }^{2}$. \\ C. Dieperink ${ }^{1}$ • P. P. J. Driessen ${ }^{1}$
}

Received: 25 November 2016 / Accepted: 20 April 2017 /

Published online: 27 May 2017

(C) The Author(s) 2017. This article is an open access publication

\begin{abstract}
The challenges of water, waste, and climate change in cities are overwhelming and underpin the importance of overcoming governance issues impeding adaptation. These "governance challenges" typically have fragmented scopes, viewpoints, and responsibilities. As there are many causes leading to this uncertainty and disagreement, there is no single best approach to solve these governance challenges. In fact, what is necessary is iterative and requires governance capacity to find dynamic long-term solutions that are supported by flexible interim targets, so as to anticipate emerging barriers and changing situations. The literature contains a plethora of governance gaps, barriers, and capacities, which sometimes overlap, are contradictory and case-specific, and reflect disciplinary scopes. We argue that a balanced set of well-developed conditions is needed, to obtain the governance capacity that enables effective change. Therefore, we aim to obtain deeper understanding of the key conditions determining the urban water governance capacity, by developing an integrated empirical-based approach that enables consistent city comparisons and facilitates decisionmaking. We propose a governance capacity framework focusing on five governance challenges: 1) water scarcity, 2) flood risk, 3) wastewater treatment, 4) solid waste treatment and 5) urban heat islands. Nine governance conditions, each with three indicators, are identified and empirically assessed using a Likert-type scoring method. The framework is illustrated by a case study on Amsterdam, the Netherlands. We conclude our approach shows great potential to improve our understanding of the key conditions determining the governance capacity to find solutions to the urban challenges of water, waste, and climate change.
\end{abstract}

\section{J. Van Leeuwen}

kees.van.leeuwen@kwrwater.nl; http://www.kwrwater.nl/

1 Copernicus Institute of Sustainable Development Utrecht University, Heidelberglaan 2, Utrecht 3584 CS, The Netherlands

2 KWR Watercycle Research Institute, Groningenhaven 7, Nieuwegein 3430 BB, The Netherlands

3 Waternet, Korte Ouderkerkerdijk 7, 1096 ACAmsterdam, The Netherlands 
Keywords Governance capacity. Watergovernance-Water management.Adaptive governance - City Blueprint $\cdot$ Social learning

\section{Introduction}

\subsection{Governance Challenges}

Cities accross the globe face huge challenges of water, waste and climate change in a rapidly urbanizing world (World Economic Forum 2016; Koop and Van Leeuwen 2016). By 2030, the world will be experiencing an estimated 40\% freshwater shortage (2030 WRG 2009). Sealevel rise, soil subsidence, and extreme river discharges pose risks to around $15 \%$ of the global population, mostly in urban areas, including almost all the world's mega-cities (Ligtvoet et al. 2014). Cities are particularly vulnerable to flooding by storm events, which are increasing in magnitude and frequency (EEA 2012). Furthermore, streams, rivers, and oceans are heavily polluted by insufficiently treated wastewater and solid waste (Derraik 2002; Ligtvoet et al. 2014), which is leading to losses of valuable resources such as phosphate (European Commission 2015). Finally, global warming is exacerbating heatwaves that pose serious health risks to people living in Urban Heat Islands (UHI): for example, it is estimated that in 2003 heatwaves were responsible for 70,000 deaths in Europe (Baccini et al. 2008). In order to combat UHI, vegetation and water bodies need to be intertwined in the urban infrastructure.

Altogether, urban areas face five main interrelated water challenges: 1) water scarcity, 2) flood risk, 3) wastewater treatment, 4) solid waste treatment, and 5) urban heat islands (EEA 2012, 2016; UCCRN 2011). Meeting these challenges requires good governance, because it entails managing long-term, complex, uncertain, and imperfectly known risks that can have large impacts. Typically, multiple governance layers (OECD 2011) and a variety of stakeholders, sectors, and policies are involved, each with different time horizons and agendas (Segrave et al. 2013). Because there are many causes that can lead to the complexity, uncertainty, and disagreement, there is no single best approach to address these governance challenges. In fact, what is necessary is an iterative process that requires governance capacity to find integrated long-term solutions that are supported by flexible intermittent targets to anticipate changing situations and adapt to emerging barriers. Hence, it is essential to manage governance challenges in an integrative long-term approach (Patterson et al. 2013).

\subsection{Knowledge Gap}

The need for integrated approaches is reflected in two main concepts: 1) Integrated Water Resources Management (IWRM), and 2) Adaptive Management (AM). IWRM aims to reshape institutional structures and redefine problems, to broaden scope. AM focuses on changing the way responsible authorities perceive and act, by emphasizing experimentation and the value of learning to adapt to changing and uncertain challenges such as climate change (Medema et al. 2008). Despite their important contributions, both approaches appear to be difficult to implement, as they are not very concrete and their explanations differ as they refer to largely undefined, complex and unpredictable processes. Moreover, they tend to be focused on more technical solutions with lesser attention to governance processes (Medema et al. 2008; Rahaman and Varis 2005; Gregory et al. 2006). Therefore, these approaches sometimes fail to provide clear and effective guidelines for their concrete application (Gregory et al. 2006). 
With respect to water management, the City Blueprint Trends and Pressure Framework and the City Blueprint Performance Framework provide integrated and strategic insights into the management performance of local authorities (Koop and Van Leeuwen 2015a, b). Furthermore, the OECD (2015a) principles of good water governance provide for an integrated network analysis of the fragmented water sector. They include analyses of international, national, and sub-national indicators and learning practices but do not focus on urban water governance.

A few worthy attempts have been made to compare organizations and institutions (Gupta et al. 2010; Ballard 2008; Engle and Lemos 2010). However, the rich literature on governance and transformation processes has a theoretical nature and only a few approach have been reported as providing tangible results to facilitate decision-making (Kersberger and Waarden 2004). At the same time, there is a seemingly endless list of social factors and conditions that impede or enhance our ability to respond proactively to future changes (Biesbroek et al. 2013). They often reflect a disciplinary scope and focus on specific case studies, which limits their usefulness and learning value (Measham et al. 2011; Plummer et al. 2012). Hence how socioeconomic factors actually influence urban governance processes largely remains an open question (Biesbroek et al. 2013) that can only be explored by applying a coherent framework that assesses different contexts consistently, provides empirical-based understanding of underlying governance processes, and searches for transferable lessons that enhance overall governance effectiveness.

\subsection{Research Aim}

In many cases, organizations or institutions are taken as the point of departure for governance assessment, whereas in practice, organizations often tend to focus on sub-tasks, lacking a full notion of their interdependencies, and underestimating the need for cooperation in addressing shared goals (Emerson et al. 2012). We argue that this is a missed opportunity, because interaction and collaboration between all relevant actors is critical. On the contrary, overly comprehensive, multi-layer governance structures that address multiple issues across different jurisdictions, proof to be difficult to analyse (Medema et al. 2008). Interestingly, the urban scale is increasingly recognized as having a crucial role in finding the most suitable solutions to address context-specific climate vulnerabilities (Measham et al. 2011; OECD 2015b). So far, little effort has been made to consistently assess the urban water governance capacity. However, such an assessment creates great potential to understand specific (local) issues and underlying processes, can provide recommendations for stakeholders, and shape learning alliances in and between cities. Here we aim to provide a deeper, integrated, and empirically-based understanding of the most important enabling conditions that determine the governance capacity needed to continuously solve governance challenges of water, waste, and climate change in urban networks. To do so, we develop a cohesive, comprehensive, and applicable Governance Capacity Framework (GCF) for cities, which can:

1. compare cities in order to develop a deeper empirical-based understanding of the key enabling governance conditions and identify transferable lessons.

2. reveal the limiting conditions and thereby formulate pathways for effective and efficient increase in the local governance capacity.

The paper is structured as follows. Section 2 provides a literature-based overview that frames and defines governance capacity. This definition is operationalized into a comprehensive framework in section 3. In section 4 a Likert-type method to score governance capacity is 
described. Section 5 provides an illustration of the first GCF pilot study in the city of Amsterdam, the Netherlands. Finally, section 6 presents the major discussion points and conclusions about the framework.

\section{Framing Governance Capacity}

Governance capacity has a rich literature in the fields of environmental governance, climate adaptation, capacity building, public administration, and water governance. An important component of governance capacity is institutional capacity: this generally focuses on how institutional setting, rules, and regulations enable actors to collaborate and address shared problems (UNDP 2008; Dang et al. 2016). Governance capacity is broader, also including resources and the role of discourses (Engle and Lemos 2010; Pahl-Wostl 2009). As it is widely recognized that governance capacity is context-dependent, definitions diverge considerably. Some emphasize integration (Emerson et al. 2012), others cooperation (Dang et al. 2016), yet others focus on flexibility (Termeer et al. 2015). We take the position that governance capacity is about enabling effective change.

The kind of change that is effective is context-dependent. For example, integration is needed whenever scopes are fragmented, whereas adaptive approaches are needed to address inflexibility, and anticipatory governance is required when responses are reactive (Segrave et al. 2016). Nevertheless, a few communalities regarding governance capacity can be identified. First, this capacity is about the ability of actors to continuously identify and jointly act on collective problems (Dang et al. 2016). Second, the capacity is determined by actors' interactions formed by social-institutional settings and allocation of resources (Pahl-Wostl 2009). Third, actors' frame of reference, including their interests, values, and culture, shape interactions and influence collective problem-solving (Adger et al. 2009). Therefore, no single governance condition is decisive. On the contrary, governance capacity is determined by a balanced set of conditions that need to be well developed. Importantly, the nature of actors' interactions is complex, unpredictable, and susceptible to external social-ecological developments. Hence, governance capacity per see does not lead to efficacious change, but rather is a precondition or enabler for effective change. Accordingly, we define water governance capacity as "the key set of governance conditions that should be developed to enable change that will be effective in finding dynamic solutions for governance challenges of water, waste, and climate change in cities".

\section{Constructing the Governance Capacity Framework}

Policy actions often appear to be ineffective, and a wide range of governance gaps or barriers have been suggested as reasons for this (e.g. Biesbroek et al. 2013; Eisenack et al. 2014). The literature has identified normative principles (e.g. OECD 2015a) and enabling or adaptive capacities to overcome barriers (e.g. UNDP 2008; Ford and King 2015). We make use of this rich knowledge base by selecting and redefining key conditions and their indicators that enable effective change, exploring their interrelations, assessing their relevance for urban water governance, and reformulating them into a well-balanced framework. We have also studied existing frameworks that analyze social processes that have inhibited or stimulated effective change in the field of urban water 
governance (Brown and Farralley 2009), river basins (Engle and Lemos 2010), water systems (Van Rijswick et al. 2014), or have a multi-level perspective (OECD 2011, 2015a; Pahl-Wostl et al. 2010). Other frameworks that have been applied in the past have concerned the adaptive capacity of institutions (Gupta et al. 2010) and organizations (Ballard 2008), or have been scale-independent (e.g. Moser and Ekstrom 2010; Ford and King 2013).

We identified key conditions for good urban water governance and classified them into three dimensions: knowing, wanting, and enabling. The "knowing" dimension refers to the need to be fully aware, understand, and learn the actual or possible risks and impacts of actions, policy, and strategic choices. We created the "wanting" dimension because actors need to commit to cooperate, express, and act upon ambitions, and apply their skills and capabilities to find solutions. Finally, the "enabling" dimension was created because actors need to have the network, resources, and instruments to enable them to implement their ambitions. The resulting framework has nine governance conditions; an in-depth literature study for each condition yielded three indicators. The results are shown in Table 1, below the findings from the literature research are described.

Table 1 The water Governance Capacity Framework (GCF). The GCF consists of nine conditions, each defined by three indicators. For each indicator, a Likert-type scoring scale has been developed, which ranges from very encouraging $(++)$ to very limiting $(-)$ to the governance capacity

\begin{tabular}{|c|c|c|}
\hline Dimensions & Conditions & Indicators \\
\hline \multirow[t]{9}{*}{ Knowing } & \multirow[t]{3}{*}{1 Awareness } & 1.1 Community knowledge \\
\hline & & 1.2 Local sense of urgency \\
\hline & & 1.3 Behavioral internalization \\
\hline & \multirow[t]{3}{*}{2 Useful knowledge } & 2.1 Information availability \\
\hline & & 2.2 Information transparency \\
\hline & & 2.3 Knowledge cohesion \\
\hline & \multirow[t]{3}{*}{3 Continuous learning } & 3.1 Smart monitoring \\
\hline & & 3.2 Evaluation \\
\hline & & 3.3 Cross-stakeholder learning \\
\hline \multirow[t]{9}{*}{ Wanting } & \multirow[t]{3}{*}{4 Stakeholder engagement . process } & 4.1 Stakeholder inclusiveness \\
\hline & & 4.2 Protection of core values \\
\hline & & 4.3 Progress and variety of options \\
\hline & \multirow[t]{3}{*}{5 Management ambition } & 5.1 Ambitious and realistic management \\
\hline & & 5.2 Discourse embedding \\
\hline & & 5.3 Management cohesion \\
\hline & \multirow[t]{3}{*}{6 Agents of change } & 6.1 Entrepreneurial agents \\
\hline & & 6.2 Collaborative agents \\
\hline & & 6.3 Visionary agents \\
\hline \multirow[t]{9}{*}{ Enabling } & \multirow[t]{3}{*}{7 Multi-level network. . potential } & 7.1 Room to manoeuvre \\
\hline & & 7.2 Clear division of responsibilities \\
\hline & & 7.3 Authority \\
\hline & \multirow[t]{3}{*}{8 Financial viability } & 8.1 Affordability \\
\hline & & 8.2 Consumer willingness to pay \\
\hline & & 8.3 Financial continuation \\
\hline & \multirow[t]{3}{*}{9 Implementing capacity } & 9.1 Policy instruments \\
\hline & & 9.2 Statutory compliance \\
\hline & & 9.3 Preparedness \\
\hline
\end{tabular}




\subsection{Condition 1: Awareness}

Awareness is a prerequisite to enable effective change. It refers to a more profound understanding of the causes, impact, and risks of governance challenges (Raaijmakers et al. 2008). Awareness is both cognitively and emotionally felt by individuals, organizations, and society (Ballard 2008) and forms the base for learning and action (Adger et al. 2009). Awareness is assessed by the indicators 1.1 community knowledge, 1.2 local sense of urgency and 1.3 behavioral internalization. Community knowledge refers to the extent to which different stakeholders possess relevant knowledge about the challenges. This is the first step in achieving conscious behavior (Gifford 2011). Local sense of urgency reflects the perception of importance of the governance challenge, which may or may not result in actions and policies (O'Connor et al. 1999). Finally, behavioral internalization indicates that a higher level of knowledge affects actors' problem- framing, goals, values, and perceptions, changing their behavior and increasing their commitment to sustainable approaches (Gifford 2011).

\subsection{Condition 2: Useful Knowledge}

The field of information science distinguishes between data, information and knowledge (Zins 2007). Data in itself is not necessarily informative, as useful knowledge can only be obtained by data interpretation and analysis (Zins 2007; Rowley 2007; Van Leeuwen 2007). Useful knowledge consists of 2.1 information availability, 2.2 information transparency, and 2.3 knowledge cohesion. Information availability refers to the extent that reliable knowledge is available. A lack of knowledge inhibits informed decision-making (Rowley 2007; Van Rijswick et al. 2014). Many cities authorities recognize the lack of knowledge of how future trends, such as urbanization and climate change, will affect them (Amundsen et al. 2010). Information transparency refers to the effective communication and sharing or co-creation of knowledge with all interested stakeholders. The information needs to be good quality, credible, understandable, and accessible for non-experts, in order to prevent miscommunication, knowledge gaps, and fragmented policy (Lemos et al. 2012; Füssel 2007). Finally, knowledge cohesion refers to the conformity of knowledge across actors, sectors, and administrative layers.

\subsection{Condition 3: Continuous Learning}

Continuous learning is required, in order to adapt to changing situations with many uncertainties, complexities, and unknowns (Folke et al. 2005). Continuous learning is assessed by 3.1 smart monitoring, 3.2 evaluation and 3.3 cross-stakeholder learning. Smart monitoring is a precondition for learning and may serve as tool for identifying alarming situations, clarifying underlying processes, and predicting future developments (Van Leeuwen 2007). Regular monitoring and evaluation are imperative for continuous learning and enhance preparedness for uncertain futures. In order to conceptualize evaluation, the theory of triple-loop learning is used, which has three levels: 1) single-loop learning which is incremental learning to refine current management and policy; 2) double-loop learning refers to the critical investigation of assumptions and key relationships, which reframes problems; 3) triple-loop learning questions underlying norms and values and can transform the wider social and institutional structure (Pahl-Wostl 2009). Finally, the third indicator, cross-stakeholder learning is crucial for learning in a public policy context, as the interaction among actors and their understanding of different perspectives lead to a more comprehensive, if not consensual, evaluation (Emerson 
et al. 2012). Furthermore, this can prevent overly limited scopes or path-dependencies (Termeer et al. 2015; Brown and Farrelly 2009).

\subsection{Condition 4: Stakeholder Engagement Process}

The importance of stakeholder engagement is widely recognized from a normative, substantive, and instrumental rationale (Glucker et al. 2013; OECD 2015a; UNDP 2008). Stakeholder engagement may lead to a more complete problem-framing and widely accepted optimized solutions for all parties involved (Pahl-Wostl 2009; Carlsson and Berkes 2005). Active stakeholder engagement is generally more time-consuming than unilateral decision-making. However, this can be more than compensated for by time gains in the implementation phase (Ridder et al. 2005). The stakeholder engagement process consists of 4.1 stakeholder inclusiveness, 4.2 protection of core values and 4.3 progress and variety of options. Stakeholder inclusiveness refers to the extent to which the representatives are able to speak and decide on behalf of all relevant stakeholders in clear and transparent engagement processes (Ford and King 2015; Ridder et al. 2005). Protection of core values refers to the importance of ensuring that all stakeholders feel confident that their core values are not harmed, in order to create a safe environment for trust relationships (Ridder et al. 2005; Pahl-Wostl et al. 2011). Therefore, it is essential that stakeholders become actively involved and commit to the process, rather than the outcome is predetermined or intermediate decisions are made early on (Folke et al. 2005). Moreover, stakeholders' contribution should influence the end-result. Progress and variety of options encompasses the prospect of gain for each stakeholder, which is ensured by clear and realistic procedures. Stakeholders should co-produce and, at the end of the process, select from a variety of options, to ensure learning and authoritative decisions (Ridder et al. 2005).

\subsection{Condition 5: Management Ambition}

Management ambition is a measure of the extent to which sustainable management and policy is interwoven with historical, cultural, normative, and political context. This is measured by assessing the sustainability ambitions within policies. Management ambition is assessed by 5.1 ambitious and realistic management, 5.2 discourse embedding, and 5.3 management cohesion. Ambitious and realistic goals need to be long-term, with intermittent measurable targets, all provided with sufficient resources and flexible mechanisms to deal with changing situations (Brown and Farrelly 2009). Discourse embedding is important, as management ambitions need to match the dominant values, discourses, and principles, in order to be successful (Van Rijswick et al. 2014). Hence, the degree to which the challenges of water, waste, and climate change are embedded in the dominant discourse, strongly determines the effectiveness of ambitious management and policy. Management cohesion assesses the level of integration between different sectoral policies and strategies, across governance levels, and between organizations. Often, the over-fragmentation of roles and responsibilities means that no single agency is in charge of water policy, and opportunities to create co-benefits are not seized (OECD 2011, 1015a; Head and Alford 2015).

\subsection{Condition 6: Agents of Change}

The concept of agents of change is often described in the fields of organizational change, AM, and innovation studies, although different terminology is used (e.g. leaders, policy 
entrepreneurs, institutional entrepreneurs; Pahl-Wostl et al. 2011; Ballard 2008; Brouwer and Biermann 2011). "Agents of change" refers to the intrinsic motivation of people, their willingness to take risks, and the support given to these efforts to change current approaches. The concept is therefore not limited to people in leading positions (Brouwer and Biermann 2011; Head and Alford 2015; Schultz and Fazey 2009). For this condition, three types of agents of change are distinguished: 6.1 entrepreneurial agents, who have the means and skills to gain access to resources, seek opportunities, and manage risks; 6.2 collaborative agents, who have the skills to build bridges and coalitions between actors; and 6.3 visionary agents, who envision long-term adaptive approaches and are able to steer current policy and actions (Brouwer and Huitema 2017; Termeer et al. 2012; Gupta et al. 2010; Ford and King 2015).

\subsection{Condition 7: Multi-Level Network Potential}

Flexible and dynamic networks are important, in order to deal with governance challenges with different interests and perspectives, and with stakeholders acting at different levels (Pahl-Wostl 2009; Gupta et al. 2010; Moser and Ekstrom 2010). Multi-level network potential consists of 7.1 room to manoeuvre, 7.2 clear division of responsibilities, and 7.3 authority. Room to manoeuvre assesses the opportunity that actors have to explore different alternative pathways, develop knowledge, and put ideas into practice. This also involves the possibility and autonomy of actors to form new fit-for-purpose partnerships that can address unconventional and emerging challenges (Gupta et al. 2010; Folke et al. 2005). Clear division of responsibilities refers to the accurate and clear division of tasks and roles for which stakeholders can be held accountable (Mees et al. 2014). Authority refers to the presence of legitimate forms of authority (e.g. embedded in policy or law), regulations, and policy networks that promote the necessity to address water-related challenges (Van Rijswick et al. 2014).

\subsection{Condition 8: Financial Viability}

Addressing urban water-related challenges requires the assurance of long-term financial support (OECD 2015b; UNECE 2009), as short budgetary cycles prevent long-term thinking (Ford and King 2015) and will most likely substantially increase overall cost (UNEP 2013; Koop and Van Leeuwen 2016). Two important aspects of financial viability are the costs and benefits of measures: e.g., who is affected, who benefits, and, therefore, who should pay (UNECE 2009). Financial viability is characterized by 8.1 affordability, 8.2 consumer willingness to pay, and 8.3 financial continuation. Affordability of water and climate adaptation services is assessed with a focus on the poor and marginalized groups (OECD 2011; UNDP 2008). Consumer willingness to pay assesses how expenditure and risks are perceived. Often, trust in local authorities and their accountability, as well as the sense of urgency or worry, are key (Raaijmakers et al. 2008). Finally, financial continuation is needed for solving long-term challenges and avoiding resources being squandered as a result of uncoordinated investments (Adger et al. 2005).

\subsection{Condition 9: Implementing Capacity}

Most studies mention policy implementation as crucial (Adger et al. 2005; Ekstrom et al. 2011; Van Rijswick et al. 2014). Implementing capacity is substantiated through 9.1 policy instruments, 9.2 statutory compliance and 9.3 preparedness. Policy instruments can be used to 
stimulate desired behavior and discourage undesired activities (Mees et al. 2014). Examples are the inclusion of the user-pays and polluter-pays principles in pricing. Continuous monitoring, evaluation, and adjustments are needed, to check and improve the effectiveness of instruments. Statutory compliance ensures that stakeholders respect and understand agreements, objectives, and legislation, which contributes to the accountability of authorities. Preparedness increases the implementation capacity, as the existence of action plans, procedures, and scripts supports policy and prepares the city for both gradual and sudden changes, events, and calamities (Gupta et al. 2010; Raaijmakers et al. 2008; Runhaar et al. 2016).

\section{Determining Levels of Governance Capacity}

Despite the rich literature on governance capacity which provides many clues, it remains a puzzle to identify gradual levels of increasing governance capacity and only a few studies explicitly described them (e.g. Gupta et al. 2010; Ballard 2008). Hence, a better understanding of these gradual levels of governance capacity is needed to provide valuable insights into key governance processes. It should also be noted that a scaling system provides cities with a better and more nuanced indication of where they are, and what steps to take to improve their capacity. For each of the twenty-seven indicators we therefore developed a Likert-type scoring system, with scores ranging from very encouraging to the overall governance capacity $(++)$ to very limiting to the overall governance capacity (--). The indicator levels were determined from a wide-ranging perusal of the literature, including AM theory (e.g. Folke et al. 2005; Engle and Lemos 2010; Gupta et al. 2010) in combination with specific theory for each condition. In addition, we included practical indicators from governance assessments and policy documents (BAGroep 2016; KING 2016). Table 2 illustrates the scoring methodology. Each of the twenty-seven indicators are scored by answering a predefined question, which are illustrated for the indicators belonging to condition 4 stakeholder engagement process. Next, the Likert-type scoring scale for indicator 4.2 protection of core values is provided. The Likert-type scoring levels, together with predefined questions, and the five main literature sources are available for each indicator at the EIP Water website (EIP Water 2017). The Likert-type scoring scale for indicator 4.2 protection of core values is based on three main aspects which together ensure that stakeholders feel confident that their core values are not harmed (Ridder et al. 2005):

1. Stakeholders need to be asked to commit to the process rather than to a predetermined outcome or intermediate decisions early in the process.

2. The existence of clear rules and procedures that have been agreed upon before the start of the engagement process, in order to ensure a sound environment in which trust relationships can be developed.

3. The actual influence stakeholders have on the end-result is important. It is largely determined by the type of stakeholder interaction, which can be conceptualized into three layers. The first layer (information supply) indicates one-way communication. The second layer (consultation) indicates that stakeholders can give feedback on developed plans. The third layer (active involvement) actively involves stakeholders throughout the policymaking and implementation process (CIS Working Group 2.9 2003). 
Table 2 Illustrative overview of the GCF scoring methodology. First, an overview of the predefined questions for the indicators belonging to condition 4 stakeholder engagement process are given. Second, the indicator 4.2 protection of core values Likert-type scoring is provided as an illustration. The predefined questions, the Likerttype scoring scale and a literature overview for each of the twenty-seven indicators are summarized at the EIP Water website (EIP Water 2017)

\begin{tabular}{|c|c|}
\hline Indicator & Predefined question \\
\hline $\begin{array}{l}\text { 4.1 Stakeholder } \\
\text { inclusiveness }\end{array}$ & $\begin{array}{l}\text { To what extent do stakeholders interact in the decision-making } \\
\text { process interaction (i.e., are merely informed, are consulted, or } \\
\text { are actively involved)? Are their engagement processes clear } \\
\text { and transparent? Are stakeholders able to speak and decide on } \\
\text { behalf of a group? }\end{array}$ \\
\hline $\begin{array}{l}4.2 \text { Protection of core } \\
\text { values }\end{array}$ & $\begin{array}{l}\text { To what extent 1) is commitment focused on the process } \\
\text { instead of on early end-results? 2) do stakeholders have the } \\
\text { opportunity to be actively involved? } 3 \text { ) are the exit procedures } \\
\text { clear and transparent? (All } 3 \text { ensure that stakeholders feel } \\
\text { confident that their core values will not be harmed.) }\end{array}$ \\
\hline $\begin{array}{l}\text { 4.3 Progress and } \\
\text { variety of options }\end{array}$ & $\begin{array}{l}\text { To what extent are procedures clear and realistic, are a variety of } \\
\text { alternatives co-created and thereafter selected from, and are } \\
\text { decisions made at the end of the process in order to secure } \\
\text { continued prospect of gain and thereby cooperative behavior } \\
\text { and progress in the engagement process? }\end{array}$ \\
\hline
\end{tabular}

\begin{tabular}{|c|c|c|}
\hline Level & Description & \\
\hline $\begin{array}{l}\text { Very } \\
\text { encouraging } \\
(++)\end{array}$ & $\begin{array}{l}\text { Maximal } \\
\text { protection of } \\
\text { core values }\end{array}$ & $\begin{array}{l}\text { Stakeholders are actively involved and co-create the end-result. } \\
\text { There are clear exit possibilities and clear process procedures. } \\
\text { All relevant stakeholders are engaged and a variety of options } \\
\text { are assessed. The final options are chosen at the end of the } \\
\text { engagement process }\end{array}$ \\
\hline $\begin{array}{l}\text { Encouraging } \\
(+)\end{array}$ & $\begin{array}{l}\text { Demand for } \\
\text { commitment } \\
\text { to early } \\
\text { output }\end{array}$ & $\begin{array}{l}\text { Stakeholders are actively involved and expected to commit to } \\
\text { early process outcomes. Hence some relevant stakeholders are } \\
\text { discouraged from committing, as not all options are being } \\
\text { assessed and at this stage the stakeholders contribution might } \\
\text { be small. The stakeholders have influence on the end-result }\end{array}$ \\
\hline $\begin{array}{l}\text { Indifferent } \\
(0)\end{array}$ & $\begin{array}{l}\text { Suboptimal } \\
\text { protection of } \\
\text { core values }\end{array}$ & $\begin{array}{l}\text { Stakeholders are consulted or actively engaged for short } \\
\text { periods. The number of options considered and influence on the } \\
\text { end-result are limited. Exit rules are vague. Decisions mainly } \\
\text { comply with the interests of the initiating party }\end{array}$ \\
\hline $\begin{array}{l}\text { Limiting } \\
(-)\end{array}$ & $\begin{array}{l}\text { Low } \\
\text { influence on } \\
\text { end-result }\end{array}$ & $\begin{array}{l}\text { Stakeholders are kept informed or consultation meetings are } \\
\text { taking place for already partly or fully elaborated plans. The } \\
\text { influence on the end-result is small and resistance may be } \\
\text { evoked }\end{array}$ \\
\hline $\begin{array}{l}\text { Very limiting } \\
(--)\end{array}$ & $\begin{array}{l}\text { Ignorance of } \\
\text { core values }\end{array}$ & $\begin{array}{l}\text { Stakeholders are hardly engaged, not informed or only informed } \\
\text { after decisions have already been made. Resistance to } \\
\text { implementation often occurs, as do distrust and lack of } \\
\text { stakeholder participation, and no clear communication }\end{array}$ \\
\hline
\end{tabular}




\section{Illustrating the Framework: Governance Capacity in Amsterdam}

\subsection{Assessing the Governance Capacity}

We applied the GCF to the five water governance challenges faced by the city of Amsterdam. Amsterdam has a complex hydrological setting: large areas are below sea level, many canals and sluices regulate the different water levels, and there is a sophisticated system for supplying drinking water, which involves infiltrating surface water into the nearby dunes.

A triangular method was applied to score indicators according to the Likert-type method. First, an analyses of policy documents and reports provided preliminary scores. Second, fifteen interviewees, three for each of the five governance challenges, were selected. To this end, the most relevant stakeholders were identified and their interdependencies were plotted, and key persons from different levels of decision-making were selected (Reed et al. 2009). As explained above, there were twenty-seven predefined questions that the research needed to answer: one for each indicator and each asked separately with respect to the five governance challenges. In this way, a consistent assessment approach was applied that enables basic comparisons to be made between, on the one hand, governance challenges, and, on the other hand, between cities. The interview questions were aimed to gather all the information needed to answer the predefined questions. They were open and non-technical, with follow-up questions to target specific elements, or to achieve further clarification. Finally, after the interviews, the participants received the predefined questions with the preliminary indicator scoring and were asked to provide constructive feedback and additional information to be included in the final scoring. The assessment was fully transparent, as the Likert-type scales, twenty-seven predefined questions, and the full list of references are publicly available.

\section{Results}

Each of the governance challenges was separately assessed and scored: from very encouraging $(++)$ to very limiting $(-)$ to the governance capacity (Table 3 ).

This first assessment suggests that Amsterdam excels in flood risk governance, and most indicators regarding water scarcity and wastewater treatment are encouraging. However, more governance capacity needs to be developed to address Urban Heat Islands (UHI), since the number of tropical days $\left(>30^{\circ} \mathrm{C}\right)$ in the Netherlands is predicted to rise substantially, from 4 days at present to $7-13$ days by 2050 and $8-21$ by 2100 (KNMI 2014). Interestingly, cities in Northern Europe appear to be most affected by the predicted rise in high temperatures, because here, temperatures will strongly exceeded the usual seasonal conditions (EEA 2012). Despite this, in the Netherlands, no separate policy on UHI has been developed so far. Consequently, Amsterdam lacks specific targets and policies regarding UHI. The lack of policy may explain the low multi-level network potential (condition 7) to address UHIs. Averaging the scores of the five challenges for each indicator yields a more general overview of Amsterdam's water governance capacity (Fig. 1). It suggests that the knowledge level of communities (indicator 1.1) and the access to understandable information for non-experts (indicator 2.2) may slightly limit local sense of urgency regarding water challenges (indicator 1.2) and consumer willingness to pay (indicator 8.2). These results are in line with the OECD 
Table 3 Overview of the twenty-seven governance indicator scores for each of the five water-related governance challenges for the city of Amsterdam. Scores range from very encouraging (++) to very limiting (-) to the city's governance capacity to find dynamic solutions

\begin{tabular}{|c|c|c|c|c|c|}
\hline & $\begin{array}{c}\text { Water } \\
\text { scarcity }\end{array}$ & Flood risk & $\begin{array}{c}\text { Wastewater } \\
\text { treatment }\end{array}$ & $\begin{array}{c}\text { Solid waste } \\
\text { treatment }\end{array}$ & $\begin{array}{c}\text { Urban heat } \\
\text { islands }\end{array}$ \\
\hline 1.1 Community knowledge & - & 0 & - & 0 & - \\
\hline 1.2 Local sense of urgency & - & ++ & - & 0 & - \\
\hline 1.3 Behavioral internalization & + & ++ & ++ & + & - \\
\hline 2.1 Information availability & ++ & ++ & 0 & 0 & 0 \\
\hline 2.2 Information transparency & 0 & 0 & 0 & - & - \\
\hline 2.3 Knowledge cohesion & + & 0 & 0 & 0 & + \\
\hline 3.1 Smart monitoring & ++ & ++ & ++ & ++ & - \\
\hline 3.2 Evaluation & ++ & ++ & ++ & ++ & - \\
\hline 3.3 Cross-stakeholder learning & + & ++ & ++ & 0 & - \\
\hline 4.1 Stakeholder inclusiveness & ++ & ++ & ++ & 0 & ++ \\
\hline 4.2 Protection of core values & ++ & ++ & 0 & + & - \\
\hline 4.3 Progress and variety of options & ++ & ++ & 0 & 0 & 0 \\
\hline 5.1 Ambitious and realistic management & + & + & + & 0 & -- \\
\hline 5.2 Discourse embedding & ++ & + & 0 & ++ & - \\
\hline 5.3 Management cohesion & ++ & + & ++ & + & - \\
\hline 6.1 Entrepreneurial agents & ++ & + & ++ & + & - \\
\hline 6.2 Collaborative agents & + & + & + & 0 & - \\
\hline 6.3 Visionary agents & + & ++ & + & 0 & + \\
\hline 7.1 Room to manoeuvre & + & + & 0 & + & 0 \\
\hline 7.2 Clear division of responsibilities & + & ++ & + & 0 & -- \\
\hline 7.3 Authority & + & ++ & + & ++ & -- \\
\hline 8.1 Affordability & + & + & + & + & + \\
\hline 8.2 Consumer willingness to pay & - & + & 0 & 0 & 0 \\
\hline 8.3 Financial continuation & + & + & + & + & 0 \\
\hline 9.1 Policy instruments & + & + & + & + & 0 \\
\hline 9.2 Statutory compliance & ++ & ++ & ++ & + & 0 \\
\hline 9.3 Preparedness & + & ++ & + & + & -- \\
\hline
\end{tabular}

(2014) analyses of the Dutch water governance, which conclude that Dutch citizens take water services for granted and that this "awareness gap" tends to decrease public involvement and the willingness to pay for water services. Therefore, the most feasible way for Amsterdam to further enable effective policy change is to focus on improving the indicator scores found to be limiting (-) or very limiting $(-)$ to the city's governance capacity.

\section{Discussion and Conclusion}

First, we will briefly discuss some limitations of the GCF. Next, we will outline the main contributions of the GCF to theory and practice and, more specifically, its role in connecting science, policy, and implementation.

\subsection{Framework Discrepancies and Reproducibility}

As governance processes are often interconnected, some of the conditions and indicators identified in our framework are inherently interrelated. Although each indicator is designed to provide an independent score, inevitably, a hypothetical "ideal" situation will not always result solely in very encouraging (++) indicator scores. For example, entrepreneurial, collaborative, and visionary agents of change (condition 6) are all relevant but their importance is 


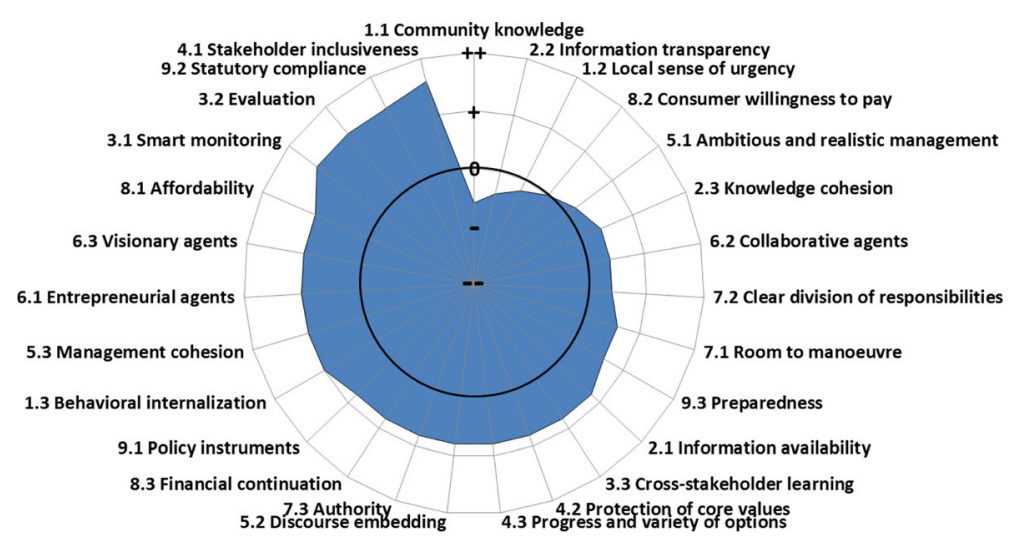

Fig. 1 Overview of the governance capacity of the city of Amsterdam. The twenty-seven indicators scores are ranked clockwise from low to high. Scores range from very encouraging (++) to very limiting (-) to the governance capacity that is a prerequisite for finding dynamic solutions to address the identified governance challenges

context-dependent (Patterson et al. 2013): visionary agents, for example, may be more necessary in times of crisis, whereas collaborative agents are more valuable in initiating new joint activities in established collaborative networks, and entrepreneurial agents operate best in open governance networks that are ambitious and flexible (Brouwer and Huitema 2017). Hence, situations may exist in which entrepreneurial and collaborative agents of change are very encouraging (++) while, as a consequence, visionary agents are less prominently active. Another important interrelation is between indicators 5.1 ambitious and realistic goals and 9.2 statutory compliance, as it is easier to comply with non-ambitious goals. Furthermore, indicators 6.1 entrepreneurial agents of change and 7.3 room to manoeuvre are reinforcing, and their scoring is interrelated. Their main difference is that entrepreneurial agents of change focuses on actors' ability and skills to create and seize opportunities, whereas the score for room to manoeuvre represents the degree of freedom and existing opportunities that actors can utilize.

\subsection{Bridging Theory and Practice}

Different time frames, reward structures, process cycles, epistemologies, and goals impede the effective use of scientific knowledge in practice (Hegger et al. 2012). Scientific knowledge is often fragmented, as it is intertwined with values, discourses, disciplinary scopes, and traditions that are often context-specific. Therefore, existing knowledge often fails to provide applicable insights that can help decision-makers achieve their intended goals and objectives. The gap between science, policy, and implementation has been widely acknowledged in water governance (OECD 2011; Medema et al. 2008; Patterson et al. 2013). Our work provides three important contributions to improve the connection between scientific knowledge, policy, and implementation in the field of water governance, climate adaptation, and beyond:

1. Integration: The GCF is one of the first attempts to integrate the plethora of contradicting, overlapping, and fragmented governance gaps, barriers, and capacities with respect to prevailing urban water challenges. It may reveal more effective and efficient pathways for cities to increase their governance capacity. At present, our understanding of underlying 
interconnections and relations is often insufficient to provide overarching pragmatic insights that facilitate decision-makers.

2. Communication: The GCF is designed to be easy to understand and transparent, and has been developed with the end-users (who include decision-makers, stakeholders, and citizens) in mind. Information needs to be understandable for them. This is essential, to facilitate constructive discussions, knowledge co-production, and cooperation.

3. City comparison: The GCF provides a framework for comparison cities and the accumulation of empirical data that can improve our understanding of underlying governance processes that limit or encourage governance capacity. At the same time, it provides a practical framework for cities to exchange learning experience, knowledge, and good practices.

Because the framework is embedded in the literature of governance and transformation processes, it is possible to assess a broader range of issues that involve processes of change in multi-organizational networks. An empirical database is currently being developed, as the GCF is being used to assess the cities of Melbourne (Australia), Quito (Ecuador; Schreurs et al. 2017), New York (USA) and Ahmedabad (India; EIP 2017). Moreover, the results of the city of Quito (Ecuador) are about to be published (Schreurs et al. 2017). The GCF has the potential to act as a portal of communication for constructive cross-city, cross-sector, and cross-stakeholder discussions, learning and theory building. Finally, the framework provides the basis for common understanding and action, by revealing the most effective and efficient pathways for increasing the governance capacity needed to address the challenges of water, waste, and climate change.

Acknowledgements Our gratitude goes to the Amsterdam water network for their participation: Roelof Kruize, Jos Ketelaars, Ingrid Heemskerk, Alice Fermont, Peter Simoës, Mark Nijman, Lex Lelijveld, Kees van der Drift, Rolf Steenwinkel, Jeroen Ponten, Martine Lodewijk, Ed Cousin, Gerard Korrel, Geertje Wijten, Maarten Claassen, Rob Koeze and Wiegert Dulfer. We thank Joy Borrough for her editorial contribution. The Governance Capacity Framework is part of City Blueprint Approach developed at KWR Watercycle Research Institute in the context of Watershare® (http://www.watershare.eu). The City Blueprint Action Group is part of the European Innovation Partnership on Water of the European Commission (http://www.eip-water.eu/City_Blueprints). The European Commission is acknowledged for Funding POWER in H2020-Water Under Grant Agreement No. 687809.

Open Access This article is distributed under the terms of the Creative Commons Attribution 4.0 International License (http://creativecommons.org/licenses/by/4.0/), which permits unrestricted use, distribution, and reproduction in any medium, provided you give appropriate credit to the original author(s) and the source, provide a link to the Creative Commons license, and indicate if changes were made.

\section{References}

Adger WN, Arnell NW, Tompkins EL (2005) Successful adaptation to climate change across scales. Glob Environ Chang 15:77-86

Adger WN, Dessai S, Goulden M, Hulme M, Lorenzoni I, Nelson DR, Naess LO, Wolf J, Wreford A (2009) Are there social limits to adaptation to climate change? Clim Chang 93:335-354

Amundsen H, Berglund F, Westskogh H (2010) Overcoming barriers to climate change adaptation-a question of multilevel governance? Environ Plan C 28:276-289

Baccini M, Biggeri A, Accetta G, Kosatsky T, Katsouyanni K, Analitis A, Anderson HR, Bisanti L, D'Ippoliti D, Danova J, Forsberg B, Medina S, Paldy A, Rabczenko D, Schindler C, Michelozzi P (2008) Heat effects on mortality in 15 European cities. Epidemiology 2:711-719

BAGroep (2016) Governance capacity measurement: How is your municipality, province or water boardfunctioning? IOP Publishing Physics Web. http://www.bagroep.nl. Accessed 23 Jan 2017

Ballard A (2008) Adaptive capacity benchmarking: a handbook and toolkit. Berkshire, Hungerford 
Biesbroek GR, Klostermann JEM, Termeer CJAM, Kabat P (2013) On the nature of barriers to climate change adaptation. Reg Environ Chang 13:1119-1129

Brouwer S, Biermann F (2011) Towards adaptive management: examining the strategies of policy entrepreneurs in Dutch water management. Ecol Soc 16:5

Brouwer S, Huitema D (2017) Policy entrepreneurs and strategies for change. Reg Environ Chang. doi:10.1007 /s10113-017-1139-z

Brown RR, Farrelly MA (2009) Delivering sustainable urban water management: a review of the hurdles we face. Water Sci Technol 59:839-846

Carlsson L, Berkes F (2005) Co-management: concepts and methodological implications. J Environ Manag 75:65-76

CIS Working Group 2.9 (2003) Common implementation strategy for the water framework directive. Guidance document, Luxembourg: Official Publications of the European Communities. https:/circabc.europa. eu/sd/a/0 fc804ff-5fe6-4874-8e0dde3e47637a63/Guidance\%20No\%208\%20-\%20Public\%20 participation\%20\%28WG\%202.9\%29.pdf

Dang TKP, Visseren-Hamakers IJ, Arts BJM (2016) A framework for assessing governance capacity: an illustration from Vietnam's forestry reforms. Environ Plann C Gov Policy 34:1154-1174

Derraik JGB (2002) The pollution of the marine environment by plastic debris: a review. Mar Pollut Bull 44:842-852

EEA (2012) European Environment Agency: urban adaptation to climate change in Europe. Challenges and opportunities for cities together with supportive national and European policies. ISBN 978-92-9213-308-5

EEA (2016) European Environmental Agency: Urban adaptation to climate change in Europe 2016. Transforming cities in a changing climate. Publication office of the European Union, Luxembourg. ISBN 978-92-9213-742-7

EIP Water (2017). European innovation partnership on water. Indicators of the Governance Capacity Framework. http://www.eip-water.eu/City_Blueprints Accessed 21 November 2016

Eisenack K, Moser SC, Hoffmann E, Klein RJT, Oberlack C, Pechan A, Rotter M, Termeer CJAM (2014) Explaining and overcoming barriers to climate change adaptation. Nat Clim Chang 4:867-872

Ekstrom JA, Moser SC, Torn M (2011) Barriers to climate change adaptation: a diagnostic framework. Project Report. California Energy Commission, Berkely

Emerson K, Nabatchi T, Balogh S (2012) An integrative framework for collaborative governance. Public Adm Res Theory 22:1-29

Engle NL, Lemos MC (2010) Unpacking governance: building adaptive capacity to climate change of river basins in Brazil. Glob Environ Chang 20:4-13

European Commission (2015) Closing the loop - an EU action plan for the circular economy. Brussels, Belgium

Folke C, Hahn T, Olsson P, Norberg J (2005) Adaptive governance of social-ecological systems. Annu Rev Environ Resour 30:441-473

Ford JD, King D (2015) A framework for examining adaptation readiness. Mitig Adapt Strateg Glob Chang 20: $505-526$

Füssel H (2007) Adaptation planning for climate change: concepts, assessment approaches, and key lessons. Sustain Sci 2:265-275

Gifford R (2011) The dragons of inaction: psychological barriers that limit climate change mitigation and adaptation. Am Psychol 66:290-302

Glucker A, Driessen PPJ, Kolhoff A, Runhaar HAC (2013) Public participation in environmental impact assessment; why, who and how? Environ Impact Assess Rev 43:104-111

Gregory R, Ohlson D, Arvai J (2006) Deconstructing adaptive management: criteria for application to environmental management. Ecol Appl 16:2411-2425

Gupta J, Termeer C, Klostermann J, Meijerink S, Van Den Brink M, Jong P, Nooteboom S, Bergsma E (2010) The adaptive capacity wheel: a method to assess the inherent characteristics of institutions to enable the adaptive capacity of society. Environ Sci Pol 13:459-471

Head BW, Alford J (2015) Wicked problems: implications for public policy and management. Adm Soc 47:711-739

Hegger D, Lamers M, Van Zeijl-Rozema A, Dieperink C (2012) Conceptualising joint knowledge production in regional climate change adaptation projects: success conditions and levers for action. Environ Sci Pol 18:52-65

Kersberger KV, Waarden FV (2004) Governance' as a bridge between disciplines: cross-disciplinary inspiration regarding shifts in governance and problems of governability, accountability and legitimacy. EJPR 43:143-171

KING (2016) Quality Institue. Dutch municipalities (in Dutch) http://www.waarstaatjegemeente.nl

KNMI (2014) Royal Dutch Meteological Institute: KNMI'14 climate cenario's for the Nederlands (in Dutch). Ministry of infrastructure and Environment. www.climatescenarios.nl

Koop SHA, Van Leeuwen CJ (2015a) Assessment of the sustainability of water resources management: a critical review of the City Blueprint approach. Water Resour Manag 29:5649-5670

Koop SHA, Van Leeuwen CJ (2015b) Application of the improved City Blueprint framework in 45 municipalities and regions. Water Resour Manag 29:4629-4647

Koop SHA, Van Leeuwen CJ (2016) The challenges of water, waste and climate change in cities. Environ Dev Sustain 19:385-418 
Lemos MC, Kirchhoff CJ, Ramprasad V (2012) Narrowing the climate information usability gap. Nat Clim Chang 2:789-794

Ligtvoet W, Hilderink H, Bouwman A, Puijenbroek P, Lucas P, Witmer M (2014) Towards a world of cities in 2050. An outlook on water-related challenges. Background report to the UN-Habitat Global Report. PBL Netherlands Environmental Assessment Agency

Measham TG, Preston BL, Smith TF, Brooke C, Gorddard R, Withycombe G, Morrison C (2011) Adapting to climate change through local municipal planning: barriers and challenges. Mitig Adapt Strateg Glob Chang 16:889-909

Medema W, McIntosh BS, Jeffrey PJ (2008) From premise to practice: a critical assessment of integrated water resources management and adaptive management approaches in the water sector. Ecol Soc 13:29

Mees HLP, Dijk J, Van Soest D, Driessen PPJ, Van Rijswick MHFMW, Runhaar H (2014) A method for the deliberate and deliberative selection of policy instrument mixes for climate change adaptation. Ecol Soc 19

Moser SC, Ekstrom JA (2010) A framework to diagnose barriers to climate change adaptation. Proc Natl Acad Sci U S A 107:22026-22031

O'Connor RE, Bord RJ, Fisher A (1999) Risk perceptions, general environmental beliefs, and willingness to address climate change. Risk Anal 19:461-471

OECD (2011) Organization for Economic Cooperation and Development: water governance in OECD countries: a multi-level approach. OECD Studies on Water, Paris

OECD (2014) Organization for Economic Cooperation and Development: water governance in the Netherlands. Fit for the future? OECD studies on water, OECD publishing

OECD (2015a) Organization for Economic Cooperation and Development: OECD principles on water governance. OECD Ministerial Council Meeting, Paris

OECD (2015b) Organization for Economic Cooperation and Development: water and cities: ensuring sustainable futures. OECD Studies on Water, Paris

Pahl-Wostl C (2009) A conceptual framework for analysing adaptive capacity and multi-level learning processes in resource governance regimes. Glob Environ Chang 19:354-365

Pahl-Wostl C, Holtz G, Kastens B, Knieper C (2010) Analyzing complex water governance regimes: the management and transition framework. Environ Sci Pol 13:571-581

Pahl-Wostl C, Nilsson C, Gupta J, Tockner K (2011) Societal learning needed to face the water challenge. Ambio 40:549-553

Patterson J, Smith C, Bellamy J (2013) Understanding enabling capacities for managing the 'wicked problem' of nonpoint source water pollution in catchments: a conceptual framework. J Environ Manag 128:441-452

Plummer R, Crona B, Armitage DR, Olsson P, Tengo M, Yudina O (2012) Adaptive comanagement: a systematic review and analysis. Ecol Soc 17:11

Raaijmakers R, Krywkow J, Van Der Veen A (2008) Flood risk perceptions and spatial multi-criteria analysis: an exploratory research for hazard mitigation. Nat Hazards 46:307-322

Rahaman MM, Varis O (2005) Integrated water resources management: evolution, prospects and future challenges. Sustain Sci Pract Policy 1:15-21

Reed MS, Graves A, Dandy N, Posthumus H, Hubacek K, Morris J, Prell C, Quinn CH, Stringer LC (2009) Who's in and why? A typology of stakeholder analysis methods for natural resource management. J Environ Manag 90:1933-1949

Ridder D, Mostert E, and Wolters HA (2005) Learning together to manage together. HarmoniCOP, Osnabrück: University of Osnabrück

Rowley J (2007) The wisdom hierarchy: representations of the DIKW hierarchy. J Inf Sci 33:163-180

Runhaar HAC, Uittenbroek CJ, Van Rijswick HFMW, HLP M, PPJ D, Gilissen HK (2016) Prepared for climate change? A method for the ex-ante assessment of formal responsibilities for climate adaptation in specific sectors. Reg Environ Chang 5:1389-1400

Schreurs E, Koop S, Van Leeuwen K (2017) Application of the City Blueprint approach to assess the challenges of water management and governance in Quito (Ecuador). Environ Dev Sustain. doi:10.1007/s10668-017-9916-X

Schultz L, Fazey I (2009) Effective leadership for adaptive management. A Practitioner's Guide, Adaptive Environmental Management, pp 295-303

Segrave AJ, van der Zouwen MW, Vierssen W (2013) Water planning: from what time perspective? Technol Forecase Soc 86:157-167

Segrave A, Brouwer S and Frijns J (2016) Understanding anticipatory water governance. Global Water Forum Termeer C, Biesbroek R, Van Den Brink M (2012) Institutions for adaptation to climate change: comparing National Adaptation strategies in Europe. EPS 11:41-53

Termeer CJAM, Dewulf A, Breeman G, Stiller SJ (2015) Governance capabilities for dealing wisely with wicked problems. Adm Soc 47:680-710

UCCRN (2011) Urban climate change research network: climate change and cities. First assessment Report of the Urban Climate Change Research Network. Cambridge University Press 
UNDP (2008) United Nations Development program: governance principles, institutional capacity and quality. New York, USA

UNECE (2009) United Nations Economic Commission for Europe: guidance on water and adaptation to climate change. Geneva

UNEP (2013) United Nations environmental program: City-level decoupling. Urban resources flows and the governance of infrastructure transition. A report of the working group on cities of the international resource panel

Van Leeuwen CJ (2007). Introduction. In: Van Leeuwen, CJ and Vermeire TG (eds) Risk Assessment of Chemicals. An Introduction, 2nd edn. Springer, Berlin, 1-36

Van Rijswick M, Edelenbos J, Hellegers P, Kok M, Kuks S (2014) Ten building blocks for sustainable water governance: an integrated method to assess the governance of water. Water Int. doi:10.1080 $/ 02508060.2014 .951828$

World Economic Forum (2016) The Global Risk Report 2016. 11the Edition. Cologny/Geneva, Switzerland

WRG (2009) 2030 water resources group: charting our water future. Economic frameworks to inform decisionmaking. West Perth, USA

Zins C (2007) Conceptual approaches for defining data, information, and knowledge. J Am Soc Inf Sci Technol $58: 479-493$ 